\title{
ANALISA DAYA DUKUNG TIANG PANCANG BETON RUMAH SAKIT BRAYAT MINULYA SURAKARTA - JAWA TENGAH
}

\author{
Dyah Setyati B. ${ }^{1^{*}}$, Anik Kustirini ${ }^{2}$, Irwan Hadi Kusumo ${ }^{3}$, Rinda Erma Wati ${ }^{4}$ \\ 1,2,3,4 JurusanTeknik Sipil Fakultas Teknik Universitas Semarang \\ Jalan Arteri Sukarno Hatta - Semarang \\ JI. SoekarnoHatta, Tlogosari , Semarang, Jawa Tengah, Indonesia \\ *e-mail :anik_krini@yahoo.co.id
}

\begin{abstract}
Planning the lower structure of the hospital must be strong, because the hospital is a place to restore health. The pile foundation serves to carry the load on the building to the ground evenly. The purpose of this study is to calculate the carrying capacity of the pole based on the strength of the soil and calculate the carrying capacity of the group pole. The foundation used in the planning of the hospital building is a type of pile foundation with a cross section dimension of $40 \times 40 \mathrm{~cm}$, with a length of $12 \mathrm{~m}$ and for the calculation of carrying capacity based on soil friction (friction). The number of piles in a pile group is 4 piles. The maximum carrying capacity of each pile meets the requirements, so that 4 piles in a pile group are safe to use.
\end{abstract}

Keywords: foundation; soil; pile; carrying capacity.

\begin{abstract}
ABSTRAK
Perencanaan struktur bawah pada rumah sakit haruslah kuat, karena rumah sakit merupakan tempat untuk memulihkan kesehatan. Pondasi tiang pancang berfungsi untuk meneruskan beban pada bangunan menuju tanah secara merata. Tujuan penelitian ini yaitu menghitung daya dukung tiang berdasarkan kekuatan tanah dan menghitung daya dukung tiang kelompok. Pondasi yang dipakai dalam perencanaan gedung rumah sakit ini adalah jenis pondasi tiang pancang dengan dimensi penampang $40 \times 40 \mathrm{~cm}$, dengan panjang $12 \mathrm{~m}$ dan untuk perhitungan daya dukung berdasarkan gesekan tanah dengan tanah (friction). Jumlah tiang pancang dalam kelompok tiang adalah 4 buah tiang pancang. Daya dukung maksimum setiap tiang pancang memenuhi persyaratan, sehingga 4 buah tiang pancang dalam kelompok tiang aman dipakai.
\end{abstract}

Kata kunci: pondasi; tanah; tiang pancang; daya dukung.

\section{PENDAHULUAN}

Rumah Sakit merupakan sebuah institusi perawatan kesehatan yang pelayanannya dilakukan oleh orang-orang profesional yaitu dokter, perawat dan tenaga ahli kesehatan lainya. Fungsi rumah sakit yaitu untuk melayani masyarakat-masyarakat yang sedang sakit ataupun korban dari kecelakaan.

Perencanaan struktur bawah pada rumah sakit haruslah kuat, karena rumah sakit merupakan tempat untuk memulihkan kesehatan. Yang perlu diperhatikan pada perencanaan, adanya kemungkinan perubahan daya dukung yang terjadi di lapangan. Oleh karena itu, struktur harus direncanakan untuk berbagai faktor keselamatan yang mungkin terjadi selama struktur, setelah struktur dan data keselamatan saat menggunakan struktur. (Alwan dan Indarto, 2010).

Pondasi tiang pancang berfungsi untuk meneruskan beban pada bangunan menuju tanah secara merata. Menurut Arifin, (2008), faktor yang menjadi dasar perhitungan pada pondasi bor pile dan pondasi tiang pancang diantaranya daya dukung tiang dan tiang kelompok, analisis dari gaya geser negatif, karena faktor-faktor ini menyebabkan tekanan 
ekstra. Pondasi pada tiang atau pondasi borpile pada umumnya mengandung ketentuan berikut: meneruskan gaya vertikal yang bekerja untuk dilanjutkan ke lapisan dasar pendukung. Dan Tambunan, J (2012) menjelaskan bahwa nilai kapasitas kelompok tiang sangat dipengaruhi oleh jumlah tiang. Semakin banyak tiang digunakan, nilai kapasitas beban meningkat.

Adapun tujuan penelitian ini yaitu menghitung daya dukung tiang dan daya dukung kelompok tiang berdasarkan kekuatan tanah.

\section{METODE PENELITIAN}

Langkah-langkah di bawah ini adalah referensi dalam menyelesaikan analisis perhitungan. Dengan demikian diharapkan langkah-langkah ini dapat diimplementasikan secara koheren, sehingga dapat menyelesaikan pekerjaan dengan baik dan benar. Metode penelitian dapat dilihat pada Gambar 1.

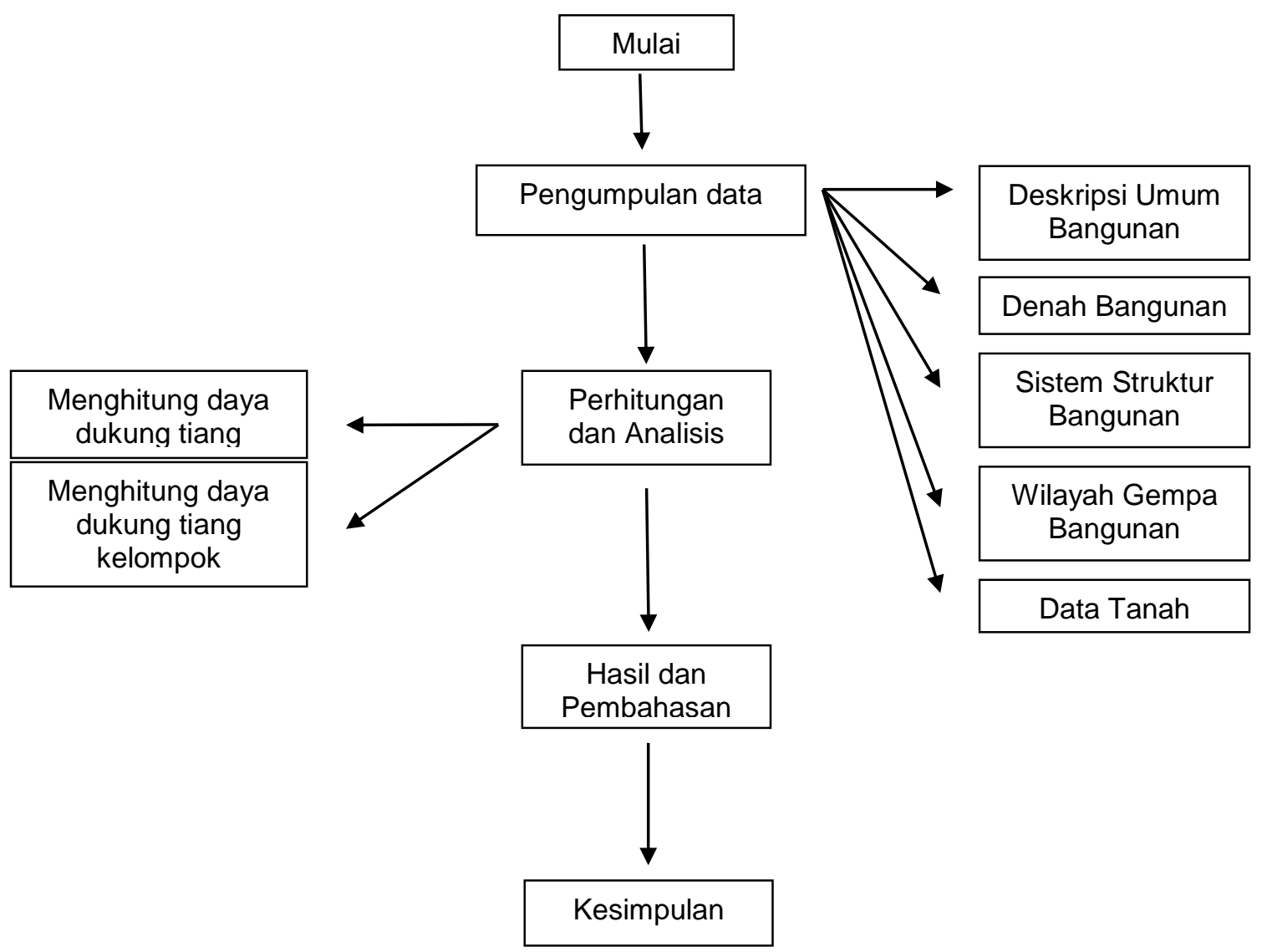

Gambar 1. Metode Penelitian

\section{HASIL DAN PEMBAHASAN}

Dalam pengerjaan perhitungan pondasi (struktur bawah) menggunakan pedoman SNI 03-2847-2002, Tata Cara Perhitungan Struktur Beton untuk Bangunan Gedung. Perhitungan pondasi direncanakan berdasarkan gaya maksimum pada kombinasi pembebanan yang ada. Pondasi yang dipakai dalam perencanaan gedung rumah sakit ini adalah jenis fondasi tiang pancang dengan dimensi penampang $40 \times 40 \mathrm{~cm}$ dan untuk perhitungan daya dukung berdasarkan gesekan tanah dengan tanah (friction). Penggunaan 
pondasi tiang kelompok direncanakan dengan jarak antar tiang tidak lebih kecil dari 2 kali diameter tiang dengan perencanaan pile cap dikelompokkan berdasarkan jumlah tiang pancang dan dimensi kolom, seperti pada Gambar 2.

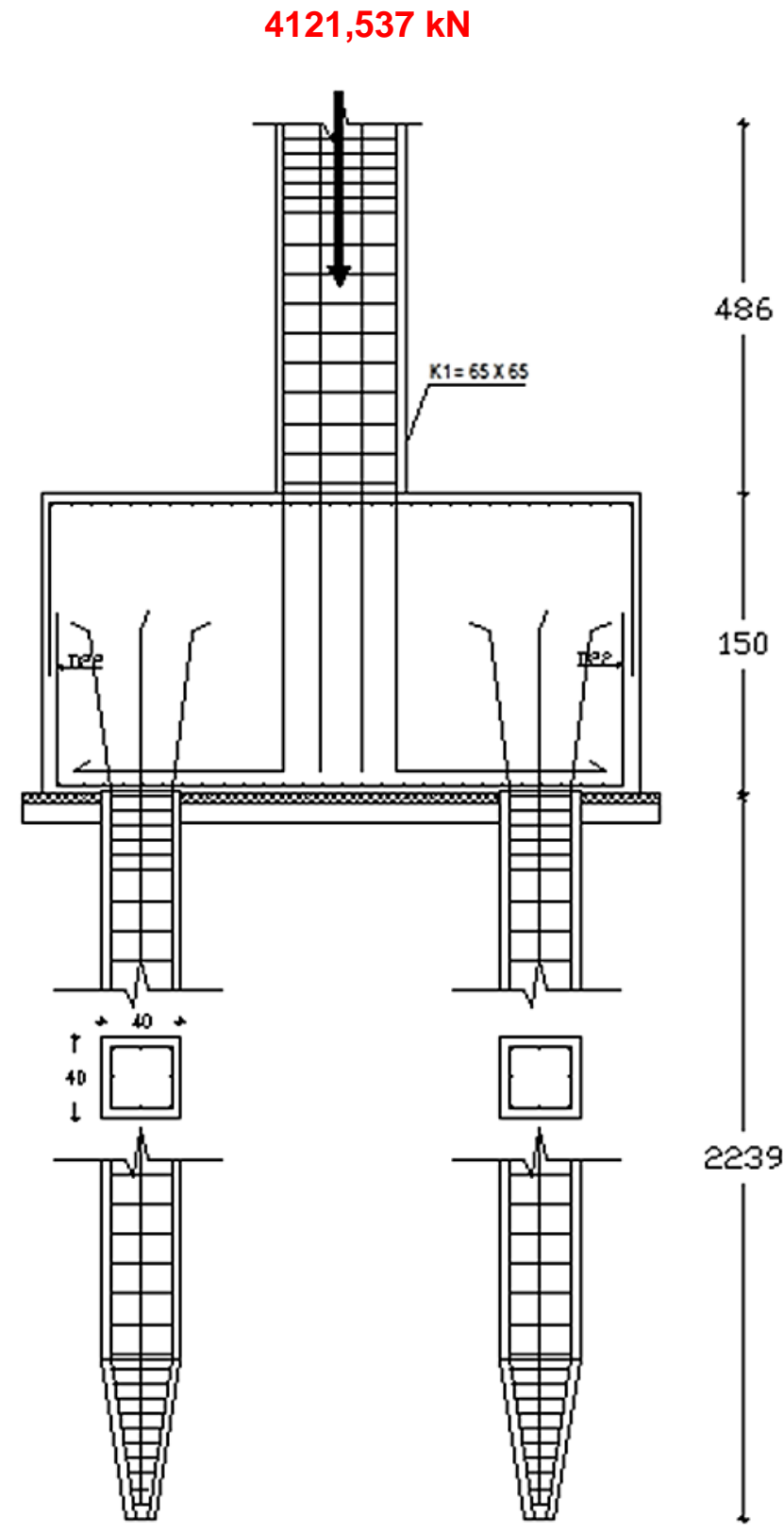

Gambar 2. Pondasi Tiang Pancang

Jenis tiang pancang yang digunakan dalam perencanaan ini adalah jenis tiang pancang fabrikasi dari produsen WIKA Beton dengan spesifikasi sebagai berikut.
Ukuran penampang
$=40 \times 40 \mathrm{~cm}$
Panjang
$\mathrm{Sb}$
$=12 \mathrm{~m}$
Klas
$=75 \mathrm{~mm}$
$\mathrm{Pa}$
$=\mathrm{A} 3$
$=180$ ton 
Data tanah berdasarkan penyelidikan tanah di dapat data Standart Penetrasion Test diuraikan pada Tabel 1.

Tabel 1. Data Standart Penetration Test

\begin{tabular}{|c|c|c|c|c|}
\hline No & Lapisan & Konsistensi & Kedalaman & $\mathbf{N}$ \\
\hline 1. & Lanau Pasiran & $\begin{array}{l}\text { Berwarna hitam kecoklatan konsistensi } \\
\text { keras }\end{array}$ & $0-2,0$ & 0 \\
\hline 2. & Pasir Kerikil & $\begin{array}{l}\text { Berwarna hitam konsistensi agak } \\
\text { padat }\end{array}$ & $2,0-2,45$ & 17 \\
\hline 3. & Pasir Lanauan & $\begin{array}{l}\text { Berwarna coklat tua konsistensi agak } \\
\text { padat }\end{array}$ & $4,0-4,45$ & 29 \\
\hline 4. & Lanau Pasiran & Berwarna abu-abu konsistensi teguh & $6,0-6,45$ & 8 \\
\hline 5. & Lempung Lanau & $\begin{array}{l}\text { Pasiran abu-abu konsistensi sangat } \\
\text { teguh }\end{array}$ & $8,0-8,45$ & 15 \\
\hline 6. & Lempung Lanau & $\begin{array}{l}\text { Berpasir berwarna abu-abu konsistensi } \\
\text { sangat teguh }\end{array}$ & $10,0-10,45$ & 10 \\
\hline 7. & Lempung Lanau & $\begin{array}{l}\text { Berpasir berwarna abu-abu konsistensi } \\
\text { sangat teguh }\end{array}$ & $12,0-12,45$ & 14 \\
\hline 8. & Pasir Kerikil & $\begin{array}{l}\text { Berwarna hitam konsistensi sangat } \\
\text { padat }\end{array}$ & $14,0-14,45$ & 48 \\
\hline 9. & Batu Pasir & $\begin{array}{l}\text { Lanauan berwarna coklat kehitaman } \\
\text { konsitensi keras }\end{array}$ & $16,0-16,40$ & 60 \\
\hline 10. & Pasir & $\begin{array}{l}\text { Kasar berkerikil berwarna hitam } \\
\text { konsistensi sangat padat }\end{array}$ & $18,0-18,25$ & 60 \\
\hline 11. & Pasir & $\begin{array}{l}\text { Kasar lanauan berwarna hitam ke abu } \\
\text { abuan konsistensi sangat keras }\end{array}$ & $20,0-20,39$ & 60 \\
\hline
\end{tabular}

(Sumber : Peneliti, 2019)

\section{Perhitungan jumlah tiang pancang pada kolom K1 (65x65)}

Jumlah tiang yang dibutuhkan dihitung dengan membagi gaya aksial perlu kolom ujung bawah dengan daya dukung tiang, pada analisis ini ditampilkan Puk pada kolom $\mathrm{K} 1$ dengan data-data :
Gaya aksial kolom Puk $=3784,037 \mathrm{kN}$

Berat poer rencana = B.L.hpoer.fc $=3.3 \cdot 1,5.25=337,5 \mathrm{kN}$

Total beban vertikal $\sum \mathrm{V}=3784,037+337,5 \mathrm{kN}=4121,537 \mathrm{kN}$

$\mathrm{Pa}$

$$
=180 \text { ton }=1800 \mathrm{kN}
$$

$\mathrm{np}=\Sigma \mathrm{V} / \mathrm{Pa}$

$=4121,537 / 1800=2,289$ maka digunakan 4 tiang

\section{Efisiensi kelompok tiang}

Pada point diatas dijelaskan analisis jumlah kebutuhan tiang, tetapi kebutuhan tiang mungkin masih belum cukup dikarenakan adanya group action yaitu intervensi garis garis tegangan tiang yang berdekatan sehingga mengurangi daya dukung kelompok tiang, yang biasanya dinyatakan dalam angka efisien.

Berikut ini analisis perhitungan dari kolom $\mathrm{K} 1$ untuk mengetahui efisiensi kelompok tiang berdasarkan rumus Converse-Labbarre dari Uniform Building Code AASHTO adalah sebagai berikut :

$$
\begin{array}{ll}
\Sigma \mathrm{V} & =4121,537 \mathrm{kN} \\
\mathrm{Pa} & =180 \text { ton }=1800 \mathrm{kN} \\
\text { Dtiang } & =0,4 \mathrm{~m}
\end{array}
$$




$$
\begin{array}{ll}
\text { Stiang } & =2,5 \cdot \mathrm{D}=2,5 \cdot 0,4=1 \mathrm{~m} \\
\Theta & =\operatorname{arctg}(\mathrm{D} / \mathrm{s})=\operatorname{arctg}(0,4 / 1)=21,8^{\circ} \\
\mathrm{M} & =2 \text { tiang } \\
\mathrm{n} & =2 \text { tiang }
\end{array}
$$

Dihitung :

$$
\begin{aligned}
& E g \quad=1-\varnothing \frac{(2-1) \cdot 2+(2-1) \cdot 2}{90 \cdot m \cdot n} \\
& E g=1-21,8 \frac{(2-1) \cdot 2+(2-1) \cdot 2}{90.2 \cdot 2} \\
& =0,758 \\
& \mathrm{P} \text { total }=\mathrm{Eg} \cdot \mathrm{np} . \mathrm{Pa} \\
& =0,758 \cdot 4 \cdot 1800 \\
& =5474,6>4121,537 \text { (Aman) }
\end{aligned}
$$

\section{Beban maksimum setiap tiang pada kelompok tiang}

Beban maksimum setiap tiang harus lebih kecil dari daya dukung izin tiang, dikontrol dengan menggunakan rumus :

$$
P \max =\frac{V}{n_{p}} \pm \frac{M_{y} \cdot X_{i}}{n_{y} \cdot \sum X^{2}} \pm \frac{M_{x} \cdot Y_{i}}{n_{x} \cdot \sum y^{2}} \leq P
$$

Keterangan :

$$
\begin{aligned}
& V=\text { jumlah gaya vertikal }(\mathrm{kN}) \\
& \mathrm{np}=\text { jumlah tiang dalam kelompok } \\
& \mathrm{My}=\text { momen terhadap sumbu-y }(\mathrm{kNm}) \\
& \mathrm{Mx}=\text { momen terhadap sumbu-x }(\mathrm{kNm}) \\
& \mathrm{xi}=\text { jarak dari pusat berat kelompok tiang ke tiang i }(\mathrm{m}) \\
& \mathrm{yi}=\text { jarak dari pusat berat kelompok tiang ke tiang i }(\mathrm{m}) \\
& \mathrm{nx}=\text { tiang sumbu-x } \\
& \mathrm{ny}=\text { tiang sumbu-y } \\
& \sum \mathrm{x}^{2}=\text { kwadrat jarak tiang }\left(\mathrm{m}^{2}\right) \\
& \sum \mathrm{y}^{2}=\text { kwadrat jarak tiang }\left(\mathrm{m}^{2}\right)
\end{aligned}
$$

Beban maksimum setiap tiang pada $\mathrm{K} 1$ dihitung sebagai berikut :

$$
\begin{array}{ll}
\mathrm{V} & =4121,537 \mathrm{KN} \\
\mathrm{Pa} & =1800 \mathrm{Kn}
\end{array}
$$




$$
\begin{array}{ll}
M x & =4410,640 \mathrm{kNm} \\
M y & =3887,641 \mathrm{kNm} \\
\mathrm{Np} & =4 \\
\mathrm{Xi}_{\mathrm{i}} & =1,00 \mathrm{~m} \\
\mathrm{Yi}_{\mathrm{i}} & =1,00 \mathrm{~m} \\
\Sigma \mathrm{x}^{2} & =2 \cdot\left(1^{2}\right)+2 \cdot\left(1^{2}\right)=4,00 \mathrm{~m}^{2} \\
\Sigma \mathrm{y}^{2} & =2 \cdot\left(1^{2}\right)+2 \cdot\left(1^{2}\right)=4,00 \mathrm{~m}^{2}
\end{array}
$$

Dihitung :

Beban yang didukung tiang no.1

$\mathrm{P} 1=\frac{4121,537}{4}+\frac{3887,641 \cdot(-1)}{2.4}+\frac{4410,640.1}{2.4}=1095,759 \mathrm{kN} \leq 1800 \mathrm{kN}$

Beban yang didukung tiang no.2

$\mathrm{P} 2=\frac{4121,537}{4}+\frac{3887,641 .(1)}{2.4}+\frac{4410,640.1}{2.4}=1607,384 \mathrm{kN} \leq 1800 \mathrm{kN}$

Beban yang didukung tiang no. 3

$\mathrm{P} 3=\frac{4121,537}{4}+\frac{3887,641 .(0)}{2.4}+\frac{4410,640.0}{2.4}=1030,384 \mathrm{kN} \leq 1800 \mathrm{kN}$

Beban yang didukung tiang no. 4

$$
\mathrm{P} 4=\frac{4121,537}{4}+\frac{3887,641 \cdot(-1)}{2 \cdot 4}+\frac{4410,640 \cdot(-1)}{2 \cdot 4}=228,75 \mathrm{kN} \leq 1800 \mathrm{kN}
$$

Dari perhitungan di atas diketahui bahwa daya dukung maksimum setiap tiang pancang memenuhi persyaratan, sehingga 4 buah tiang pancang dalam kelompok tiang aman dipakai.

\section{KESIMPULAN}

Perencanaan Rumah Sakit Brayat Minulya bagian struktur pondasi mengunakan perhitungan manual dengan N SPT, dalam mendesain pondasi diharuskan melihat daya dukung tanah yang akan terjadi di lapangan dan penyelidikan tanah dari hasil Borlog, perencanaan tiang pancang menghasilkan 4 buah tiang pancang pada kolom dimensi $65 \mathrm{x}$ $65 \mathrm{~cm}$, dengan menggunakan dimensi pile cap $L=2,5 \mathrm{~m}, P=2,5 \mathrm{~m}$, dan $T=1 \mathrm{~m}$, semakin besar kolom maka akan semakin banyak juga tiang pancang yang digunakan, hal ini terjadi karena semakin beratnya momen yang dipikul kolom tersebut.

\section{DAFTAR PUSTAKA}

Alwan,I., dan Indarto. (2010). Pengaruh Variasi Kadar Air Terhadap Daya Dukung Pondasi Tiang Type Friction Pile pada tanah Ekspansif, ITS Master 10733 Paper.

Arifin. (2008). Analisa Perbadingan Biaya Pelaksanaan Pondasi Tiang Pancang dan Bor Pile Jembatan Suramadu, Neutron, Vol.8, No.2, Agustus :1-13. 
Badan Standarisasi Nasional. (1991). Tata Cara Perhitungan Struktur Beton Untuk Bangunan Gedung, SNI 03-2847-2002.

Hardiyatmo, Hary C. (2011). Analisis \& Perancangan Fondasi II, Bandung : Gadjah Mada University Press.

Lilies, W. (2015). Analisa Dan Desain Pondasi Tiang Pancang Berdasarkan Bentuk Tiang, Jurnal Teknik Sipil, Vol. 6, No. 2.

Manoppo, F., J. (2010). Perilaku Tiang Pancang Miring Pada Daya Dukung Tiang Pancang Kelompok Akibat Beban Vertikal Di Tanah Pasir, Media Teknik Sipil, Vol.18, No.1: 31-40.

Nugroho, S.,A. (2011). Studi Daya Dukung Pondasi Dangkal pada Tanah Gambut dengan Kombinasi Geotekstil dan Grid Bambu, Jurnal Teknik Sipil, Vol. 18 No. 1,: 31-40.

Tambunan, J. (2012). Analisis Daya Dukung Pondasi Tiang Pancang, Jurnal Rancang Sipil, Vol. 1, No. 1,:1-10.

Tindaon, T. (2014). Analisa Daya Dukung dan Penurunan Elemen Tiang Pancang Beton $\varnothing 0,5 \mathrm{~m}$ Jembatan Sungai Penara Jalan Akses Non-Tol Kualanamu, Tugas Akhir.

Ukiman. (2011). Penurunan Daya Dukung Tahanan Selimut Pondasi Tiang pada Tanah yang Mengalami Pembasahan, Orbith, Vol. 7,No. 3: 383-387. 